\title{
Assessment of Erysiphe necator Ascospore Release Models for Use in the Mediterranean Climate of Western Oregon
}

L. D. Thiessen, ${ }^{\dagger}$ Department of Botany and Plant Pathology, Oregon State University, Corvallis 97331; and T. M. Neill and W. F. Mahaffee, United States Department of Agriculture-Agricultural Research Service, Horticultural Crops Research Laboratory, Corvallis, OR 97331

\begin{abstract}
Predictive models have been developed in several major grape-growing regions to correlate environmental conditions to Erysiphe necator ascospore release; however, these models may not be broadly applicable in regions with different climatic conditions. To assess ascospore release in near-coastal regions of western Oregon, chasmothecia (syn. cleistothecia) were collected prior to leaf drop and placed onto natural and artificial grape trunk segments and overwintered outside. Ascospore release was monitored for three overwintering seasons using custom impaction spore traps from leaf drop (Biologische Bundesanstalt, Bundessortenamt und Chemische Industrie $[\mathrm{BBCH}]$ 97) until the onset of the disease epidemic in the following growing season. Airborne inoculum was concurrently monitored in a naturally infested research vineyard. Weather and ascospore release data were used to assess previously developed models and correlate environmental conditions to ascospore release. Ascospore

release was predicted by all models prior to bud break (BBCH 08$)$ and was observed from the first rain event following the start of inoculum monitoring until monitoring ceased. Previously developed models overpredicted ascospore release in the Willamette Valley and predicted exhaustion of inoculum prior to bud break. The magnitude of ascospore release could not be correlated to environmental conditions; thus, a binary ascospore release model was developed where release is a function of the collective occurrence of the following factors within a 24-h period: $>6 \mathrm{~h}$ of cumulative leaf wetness during temperatures $>4^{\circ} \mathrm{C}$, precipitation $>2.5 \mathrm{~mm}$, and relative humidity $>80 \%$. The Oregon model was validated using field-collected ascospore datasets, and predicted ascospore release with 66\% accuracy $(P=0.02)$. Extant methods for estimating ascospore release may not be sufficiently accurate to use as predictive models in wet, temperate climatic regions.
\end{abstract}

Primary inoculum for polycyclic phytopathogens initiates the disease epidemic, and the timing of inoculum release affects the severity of the disease epidemic (Madden et al. 2007). In order to reduce the impact of polycyclic diseases in agricultural systems, growers attempt to delay disease onset or reduce the epidemic rate by applying pesticides on a calendar schedule or timed utilizing disease risk assessments (Madden et al. 2007; Thiessen et al. 2016). Grape powdery mildew, caused by Erysiphe necator Schwein.(Braun and Takamatsu 2013), is a polycyclic disease that damages grape (Vitis vinifera L.) worldwide and is managed by initiating fungicide applications soon after bud break (phenological growth stage Biologische Bundesanstalt, Bundessortenamt und Chemische Industrie [BBCH] 08) Lorenz et al. (1995). Ascospores released from chasmothecia (syn. cleistothecia) are the primary inoculum source for grape powdery mildew in most grape-growing regions (Cortesi et al. 1997; Gee et al. 2000; Grove 2004; Pearson and Gadoury 1987; Rossi et al. 2010; Thiessen et al. 2016). Chasmothecia are formed in the previous growing season on green tissues and are then dispersed to the exfoliating bark of the grape host (Gadoury and Pearson 1988), where chasmothecia overwinter until conducive conditions for ascospore release are met. Maturation of chasmothecia is required for release, which appears to be dependent upon degree-day accumulation during development and overwintering (Gadoury and Pearson 1988; Gee

${ }^{\dagger}$ Corresponding author: L. D. Thiessen; E-mail: ldthiess@ ncsu.edu

Funding: This work was supported by the American Vineyard Foundation, Oregon Wine Board, and United States Department of Agriculture-Agricultural Research Service CRIS 5358-22000-039-00D.

The use of trade, firm, or corporation names in this publication is for the information and convenience of the reader. Such use does not constitute an official endorsement or approval by the United States Department of Agriculture or the Agricultural Research Service of any product or service to the exclusion of others that may be suitable.

Accepted for publication 11 February 2018.

This article is in the public domain and not copyrightable. It may be freely reprinted with customary crediting of the source. The American Phytopathological Society, 2018. et al. 2000; Legler et al. 2012; Rossi et al. 2010). Once mature, ascospore release from chasmothecia in the field has been shown to occur after $\geq 2.5 \mathrm{~mm}$ of rain and at temperatures above $4^{\circ} \mathrm{C}$ (Gadoury and Pearson 1990a). In order to estimate the occurrence and severity of ascospore release, Thomas et al. (1994) modified the Mills' apple scab table by multiplying the values by two-thirds; however, these conditions do not always predict disease onset in the wet, Mediterranean climate of the Willamette Valley in western Oregon (Hall 2000).

Because management efforts are required before E. necator signs are readily detectable through scouting, several disease forecasting models have been developed to predict primary inoculum release as a function of environmental conditions to aid in management decisions (Caffi et al. 2011; Gee et al. 2000; Jailloux et al. 1999; Moyer et al. 2014; Rossi et al. 2010; Thomas et al. 1994). However, several of the disease prediction models inaccurately predict early disease onset for the Willamette Valley of Oregon (Pscheidt et al. 2000), and others (Caffi et al. 2011; Moyer et al. 2014) have not been tested extensively outside their region of development. The Mediterranean climate (Csb) (Kottek et al. 2006) observed in the Willamette Valley of Oregon is characterized by warm, dry summers and moderate, wet winters, which may affect the accuracy of models developed in other regions. Additionally, previously developed models are derived from environmental conditions that generally differ from those of the western coastal and near-coastal viticulture regions of the United States, and predictions may not accurately describe fungal overwintering, maturation, and ascospore release.

Models published to date do not accurately represent the loss of initial inoculum during grape dormancy in regions with warm, wet climates. The mechanistic model described by Caffi et al. (2011) only accounts for loss of inoculum during grape dormancy after 1 January, and was validated using simulated conidia data from Chellemi and Marois (1991), ascospore release from a single temperature (Gadoury and Pearson 1990a), or observed conidia germination data (Delp 1954). Furthermore, this model predicts the proportion of ascospores available for release based on degree-days from time that primordia are observed in the previous growing season, a parameter that is difficult to determine in practice and not likely to be implemented by growers. The ascospore release model developed by Moyer et al. (2014) accounts for loss of inoculum during overwintering; however, 
this model is based on induced ascospore release under optimal conditions in the laboratory from chasmothecia that have overwintered in field conditions. These limitations could affect the accuracy and sensitivity of these models to predict ascospore release in the field and as a tool for timing disease management practices.

The primary purpose of this study was to assess the environmental factors affecting primary inoculum release in a region with temperate overwintering conditions and frequent rains. The specific objectives of this research were to (i) determine when ascospore release within the Willamette Valley of Oregon occurs, (ii) examine the fit of previously developed ascospore release models to ascospore release observed within this region, and (iii) determine the environmental factors associated with ascospore release in the Willamette Valley of Oregon.

\section{Materials and Methods}

Chasmothecia collection. For all experiments, leaves infested with chasmothecia were collected from a research vineyard and three different commercial vineyards at various locations in the Willamette Valley of Oregon in early October (BBCH 92), prior to the first rain and leaf drop of each year. Leaf drop was characterized as 100\% defoliation within the research vineyard to reduce potential for collecting conidia, which are indistinguishable from ascospores using the quantitative polymerase chain reaction (qPCR) assay. Complete leaf drop occurred on 22 November 2012, 15 November 2013, and 1 November 2014. To prevent artificial wetting and drying cycles, chasmothecia were vacuumed from leaf surfaces into sterile, $15-\mathrm{ml}$ plastic tubes and stored at $4^{\circ} \mathrm{C}$ until placed in experimental conditions. Leaves contained chasmothecia from all stages of maturation, and the chasmothecia were not separated by maturation stage.
Ascospore overwintering and monitoring. An array of seven open-air boxes with top and bottom open and sides enclosed was created using twin-wall polycarbonate greenhouse sheeting (Fig. 1A). A custom impaction spore sampler was suspended in the center of each array box using 2-cm-diameter PVC (Fig. 1C) and connected to a power control board similar to that of Thiessen et al. (2016). Within each array box, a 15.3-cm-length of grape trunk or artificial bark was suspended above each spore sampler $61 \mathrm{~cm}$ from the ground to mimic the height of a grape trunk head or cordon. Artificial bark pieces were included in the experiment to remove potential influences from other microorganisms that may be present on grape trunk pieces. The artificial bark pieces consisted of brown tweed-wool fabric covering wooden dowels $(15.3 \mathrm{~cm}$ long by $3.2 \mathrm{~cm}$ in diameter). The wool had wetting and drying properties similar to grape bark, as tested by monitoring changes in electrical resistance during natural wetting and drying (described below).

Stainless steel sampling rods (1.1 $\mathrm{mm}$ in diameter by $36 \mathrm{~mm}$ long) were cut from 308LSI welding rods (Weldcote Metals, Kings Mountain, NC) and cleaned, coated in a very thin layer of silicone vacuum grease (Dow Corning Corporation, Auburn, MI), and stored as described by Thiessen et al. (2016).

Collected chasmothecia were subsampled using an antistatic polypropylene microscoop (Tradewinds Direct, Inc., Pleasant Prairie, WI). A single scoop of chasmothecia was suspended in $1 \mathrm{ml}$ of deionized water and the concentration of all chasmothecia per microscoop estimated using a hemocytometer. Each artificial trunk piece (described above) was inoculated with $10^{3}$ chasmothecia by measuring dry-collected chasmothecia with a microscoop and mechanically embedding the chasmothecia into the substrate with gentle rubbing.
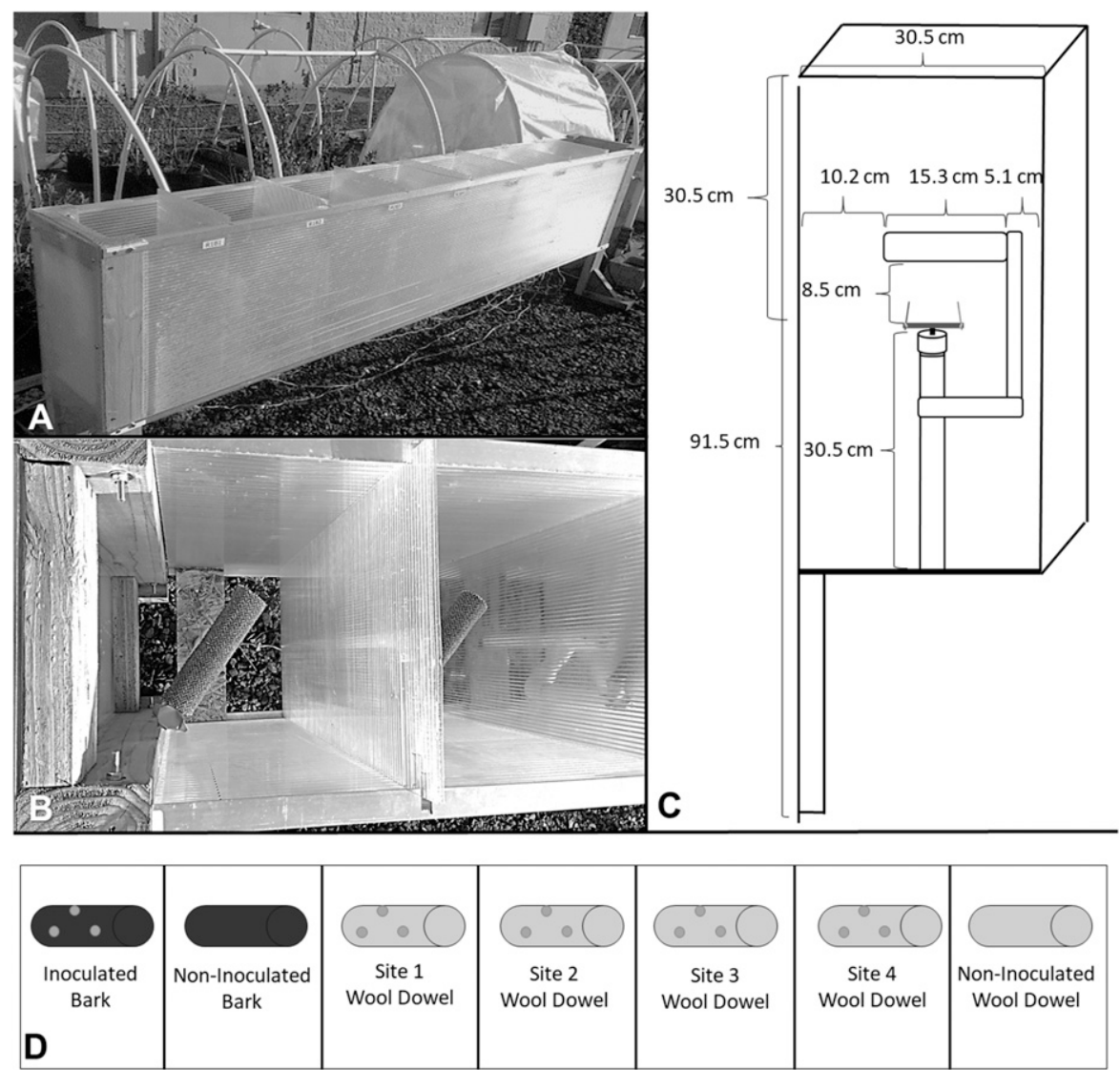

Fig. 1. Ascospore trapping array design. A, Four separate ascospore sampling arrays were arranged in a region with no grape plants nearby to avoid potential conidial contamination. D, Each array contained seven separate treatment boxes and C, a spore sampler was contained below surrogate bark or grape trunk segment (15.3 $\mathrm{cm}$ long) artificially infested with chasmothecia of Erysiphe necator. Surrogate bark consisted of wooden dowels (15.3 cm long by $3.8 \mathrm{~cm}$ in diameter) covered in brown wool. B, Individual boxes were 30.5 by 30.5 by $91.5 \mathrm{~cm}$, and the wool dowel or trunk pieces were suspended above the spore sampler in the center of each box. Spore samplers were run constantly and sampling rods were collected and replaced every 3 or 4 days. Each array contained chasmothecia collected from four vineyards within the Willamette Valley of Oregon embedded in surrogate bark, inoculated bark, and noninoculated bark and surrogate bark pieces to quantify exogenous sources of inoculum (D). All treatments were randomized within each array replicate. 
Natural grape trunk pieces cut to $15.3 \mathrm{~cm}$ in length were also inoculated with $10^{3}$ chasmothecia collected from the research vineyard, as described above. Confirmation of ascocarp embedment into the substrate was confirmed microscopically. Each box included one of seven treatments: chasmothecia from one of the four vineyards sampled on artificial bark accounted for four treatments, a nontreated artificial bark control that contained no chasmothecia, a natural bark treatment containing chasmothecia from the research vineyard, and a nontreated natural bark control that contained no chasmothecia. Four replications of each location were placed in a randomized complete block design, with each seven-box array as the block (Fig. 1D).

Ascospore trapping arrays were maintained outdoors away from known sources of $E$. necator from the onset of precipitation events following $100 \%$ leaf drop (BBCH 97) in the Willamette Valley until the following spring, when ascospore release was exhausted, or by 1 July, whichever came first. The first year of sampling was delayed until February 2013 due to construction and troubleshooting of the ascospore array boxes, and chasmothecia collected in 2012 were stored in $4^{\circ} \mathrm{C}$ in dry conditions until placement in the array. Custom impaction spore samplers were run constantly and rods were collected on Mondays and Thursdays (biweekly) throughout the duration of the experiment. Collected rod samples were stored at $-20^{\circ} \mathrm{C}$ until processing. The data derived from these samples were used as the development dataset for the model developed below.

An additional three custom impaction spore samplers (Thiessen et al. 2016) were placed at the Botany and Plant Pathology Research vineyard adjacent to grape trunks naturally infested with $E$. necator chasmothecia. Field traps were run continuously and collected biweekly from $100 \%$ leaf drop (BBCH 97, mid- to late November) until disease was observed in the following growing season. Collected spore rods were stored at $-20^{\circ} \mathrm{C}$ until processing. The data derived from these samples were used as the testing data set for validation of the model developed below.

Ascospore enumeration. A standard spore quantification curve and positive controls for each assay were produced by coating rods pairs with known quantities of conidia (Thiessen et al. 2016). The conidia suspensions of E. necator were created by suspending spores in sterile $0.05 \%$ Tween 20 (Sigma Aldrich, St. Louis) in deionized water. The spore suspension was pipetted onto rod pairs such that $100,500,1,000$, or 10,000 spores were present on the rods. To accurately produce 1 - and 10 -spore conidia concentrations, conidia were manually transferred to sterile rod pairs using an eyelash brush. The rods were allowed to air dry prior to processing or storage at $-20^{\circ} \mathrm{C}$. Five separate spore dilution series were used to generate the standard curve (described below). Although the asexual spore stage was used to generate the standard curve and qPCR assay (described below), ascospores had the same number of copies of the target region and amplification was similar to that of conidia (personal observation).

DNA from array samples and positive control rods was extracted by modifying a quick extraction technique (Thiessen et al. 2016). Spore rods were placed into $2-\mathrm{ml}$ tubes containing $200 \mu \mathrm{l}$ of $5 \%$ Chelex 100 (Sigma Aldrich) in diethyl-pyrocarbonate-treated water. Tubes were vortexed for $5 \mathrm{~s}$, then boiled in deionized water for $5 \mathrm{~min}$; this was repeated for two cycles. Tubes were allowed to cool for $2 \mathrm{~min}$ prior to centrifugation at $16,000 \times g$ for $2 \mathrm{~min}$. The rods were aseptically removed from the tubes and discarded. A set of rods inoculated with 500 E. necator conidia was included in each set of DNA extractions as an extraction efficiency control. The supernatant was used as template for the qPCR described below and stored at $-20^{\circ} \mathrm{C}$.

qPCR protocols were modified from those of Thiessen et al. (2016) to accommodate a larger DNA extraction volume. Species-specific primers (Unc144 and Unc511) developed by Falacy et al. (2007) were used in conjunction with the Unc TaqMan probe with minor groove binder (Thiessen et al. 2016). All qPCR were conducted on an ABI StepOne Plus qPCR machine (Applied Biosystems, Grand Island, NY). Each reaction included $7.5 \mu l$ of PerfeCTa qPCR ToughMix (Quanta Biosciences, Gaithersburg, MD) and $400 \mathrm{nM}$ final concentration of forward and reverse primers and TaqMan probe in a $15-\mu 1$ reaction, with $3 \mu 1$ of DNA template. PCR conditions were $95^{\circ} \mathrm{C}$ for $15 \mathrm{~s}$ followed by 55 cycles of $95^{\circ} \mathrm{C}$ for $15 \mathrm{~s}$ and $65^{\circ} \mathrm{C}$ for $40 \mathrm{~s}$.
Every reaction plate contained a 500 conidia-extraction efficiency control, 100 and 10,000 conidia-positive controls, and a templatefree negative control. All reactions were performed in triplicate. Data collection and cycle threshold $\left(\mathrm{C}_{\mathrm{t}}\right)$ analysis were conducted using the ABI StepOne software. The threshold value was manually set to 0.02 to allow for reaction plate relative comparison. The baseline was only manually manipulated when the automatic baseline value yielded abnormal amplification curves, which occurred rarely. Quantification of conidia was determined for each unknown by determining the average $C_{t}$ value for each triplicate reaction and comparing it with the standard curve. The standard curve was generated by extracting five separate E. necator conidia dilution series prepared as described above, and the $\mathrm{C}_{\mathrm{t}}$ value for each conidia quantity was determined. All unknown spore quantities were compared with the standard curve to determine spore quantity, and positive controls were compared with the standard curve to confirm the efficiency of each extraction and reaction plate.

Environmental monitoring and data collection. Relative humidity, temperature, rainfall, leaf wetness measurements collected from capacitance (LWS; Decagon, Pullman, WA) and resistance (237-L; Campbell Scientific, Logan, UT) leaf wetness sensors, and bark wetness (described below) were measured at 5-min intervals throughout the duration of the experiment using Campbell Scientific CR10X data loggers. The wetting and drying of the artificial bark and natural grape bark were compared using resistance leaf wetness sensors (IM521CD; Pessl Instruments, Weiz, Austria). The filter paper portion of these sensors was replaced with either a piece of brown tweed wool or excised grape bark ( 5 by $2 \mathrm{~cm}$ ), and resistance was measured every $5 \mathrm{~min}$.

Comparison of ascospore release models. Models (described below) were tested using the weather data collected throughout the duration of grape dormancy in each year of this study (2013 to 2015). Among all three replicated spore samplers in the naturally infested research vineyard, if two of the three samplers had positive detections, an ascospore release event was considered to have occurred. The average observed natural ascospore release events from the research vineyard spore samplers were used to validate all models tested. After predicted ascospore release was determined for each model, predictions were summarized to the same time scale as the ascospore collection dates to compare predicted and observed ascospore release for each year. All data were analyzed using $\mathrm{R}$, version 3.2.1.

Models that resulted in binary data (Gadoury and Pearson 1990a; Gubler et al. 1999) were compared using receiver-operator characteristics. The sensitivity, specificity, accuracy, and Fisher's exact test was used to compare predicted and observed ascospore release (Fawcett 2006). The sensitivity was calculated as [ 1 - (false positive/total negative) $]$ and the specificity as [1 - (false negative/total positive)]. The accuracy was calculated as [(true positive + true negative)/total observations]. The misclassification rate was calculated as [(false positive + false negative)/total observations]. From the two-by-two contingency table, a Fisher's exact test was conducted, whereby the qPCR assay detection was assumed to be correct for the detection of E. necator ascospore DNA on the sampling rods; the null hypothesis for the Fisher's exact test was that results of the models and qPCR assays were not correlated.

Models generating the magnitude of ascospore release (Caffi et al. 2011; Moyer et al. 2014) were compared by linear regression correlating model predictions to observed ascospore release magnitude. The coefficient of determination $\left(R^{2}\right)$ and Spearman's rankcorrelation $(\rho)$ were calculated for each model tested in the three sampling periods. Additionally, models that predicted magnitude were assessed for predicting binary ascospore release, and the accuracy, misclassification rate, sensitivity, and specificity were calculated as above. A Fisher's exact test was assessed on the binary predictors of models as described above.

University of California Davis risk index. This model was chosen because of its widespread use in grape-producing regions of the United States to time fungicide applications. The University of California (UC) Davis Risk Index describes ascospore release and 
germination using two-thirds of the value from the Mills table for apple scab (Gubler et al. 1999; Thomas et al. 1994). The resulting index from the full model is categorical, and ascospore release event data are binary.

Gadoury and Pearson ascospore release model. Although the original intent of Gadoury and Pearson (1990a) was not for an ascospore release model, their expert rule was chosen due to its influence on other disease models developed since and widespread use by grape producers in the United States to time initial fungicide applications. The Gadoury and Pearson model describes ascospore release and infection as a function of $2.5 \mathrm{~mm}$ of rain or irrigation when temperature is between 10 and $27^{\circ} \mathrm{C}$ (Gadoury and Pearson 1990a). Ascospore release was shown to occur from 4 to $27^{\circ} \mathrm{C}$, and these parameters were used for assessing ascospore release in the Willamette Valley. The resulting risk index is binary.

Moyer et al. ascospore release model. This model was chosen due to its recent publication and potential utility in Western Oregon. The ascospore release model (equation 1) from Moyer et al. (2014) describes percentage of seasonal total ascospore release as a function of accumulated degree-days with a base of $0^{\circ} \mathrm{C}\left(\mathrm{DD}_{0}\right)$ beginning 1 January and the number of potential discharge events (PDE). PDE is defined as the number of days whereby rainfall is $\geq 2.5 \mathrm{~mm}$ and the daily average temperature is above $0^{\circ} \mathrm{C}$.

$$
\begin{aligned}
\text { Percent release }= & 1-\exp [-\exp (-3.335+0.00222) \\
& \left.\left(\mathrm{DD}_{0}+0.150287 \times \mathrm{PDE}\right)\right]
\end{aligned}
$$

Caffi mechanistic model. This model was chosen due to its mechanistic stepwise description of ascospore development and release and its incorporation of modeling inputs from several other studies (Delp 1954; Gadoury and Pearson 1988, 1990a,b; Rossi et al. 2010). The mechanistic model described by Caffi et al. (2011) uses ascospore release and subsequent infection to predict the development of sporulating E. necator colonies on grape leaves. For this analysis, only the portions of the model describing ascospore release (equations 2 to 4 from Caffi et al. 2011) were examined. Although the error of constants is described for each equation of the model, only the deterministic means were used to test field collected ascospores. Although this model was developed to predict ascospore release after bud break (BBCH 08), the model was initiated at the start of field ascospore collection in this study due to the potential for ascospore release prior to bud break. The model was not tested starting at bud break due to the potential for the reduced sample size to affect statistical power and relationship of predicted versus observed values.

The model describes ascospore release as a function of the proportion of ascospores ready for release $\left(\mathrm{PAR}_{\mathrm{i}}\right.$; equation 2$)$, the number of ascospores in chasmothecia (AIC; equation 3), ascospore maturation rate (AMR; equation 3), and the ascospore discharge rate (ADR; equation 4). Degree-days with a base of $10^{\circ} \mathrm{C}\left(\mathrm{DD}_{\mathrm{i}}\right)$ are calculated by using the day of the year at bud break $\left(\mathrm{DOY}_{\mathrm{bb}}\right)$ for each sampling season to assess the portion of $\mathrm{PAR}_{\mathrm{i}}$.

$$
\begin{aligned}
& \operatorname{PAR}_{\mathrm{i}}= \exp \{(-1.95 \pm 0.188) \\
&\left.\times \exp \left(\left[(-1.91 \pm 0.293) \times \mathrm{DD}_{\mathrm{i}}\right] / 100\right)\right\} \\
& D D_{i}=\sum_{D O Y_{b b}}^{i}\left(T_{i}-10\right) ; \quad \text { if } \quad \mathrm{T}_{i}-10<10, \text { then } D D_{i}=0
\end{aligned}
$$

The number of overwintering chasmothecia $(\mathrm{OCH})$ will be unknown in any commercial implementation; therefore, this number was set to 1 within the model and expressed as a percentage of total chasmothecia.

$$
A I C=\sum_{D O Y_{b b}}^{i}(A M R \cdot O C H)
$$

AMR $=\mathrm{f}^{\prime}(\mathrm{PAR})$, where $\mathrm{f}^{\prime}(\mathrm{PAR})$ is the first derivative of PAR.

Ascospore release is inferred from the presence of ascospores on leaves (AOL; equation 4). The ADR is a function based on the condition of $2 \mathrm{~mm}$ of precipitation $\left(\mathrm{R}_{\mathrm{i}}\right)$ occurring on day $i$ and temperature $(\mathrm{T})$ between 4 and $30^{\circ} \mathrm{C}$. If conditions for release are met, ascospore discharge depends on temperature and wetness duration (W; hours).

$$
\mathrm{AOL}_{\mathrm{i}}=\mathrm{AIC}_{\mathrm{i}} \times \mathrm{ADR}_{\mathrm{i}}
$$

If $\mathrm{R}_{\mathrm{i}}<2 \mathrm{~mm}$ or $\mathrm{T}<4^{\circ} \mathrm{C}$ or $\mathrm{T}>30^{\circ} \mathrm{C}, \mathrm{ADR}_{\mathrm{i}}=0$.

When precipitation $\geq 2 \mathrm{~mm}$ or $\mathrm{T} \geq 4^{\circ} \mathrm{C}$ or $\mathrm{T} \leq 30^{\circ} \mathrm{C}, \mathrm{ADR}=1-$ $0.969 \pm 0.024 \times \exp \left(-0.0004 \pm 0.00003 \times \mathrm{T}^{2} \times \mathrm{W}\right)$.

Environmental factors affecting ascospore release. Data analysis was conducted in the $\mathrm{R}$ environment (version 3.2.1) using multiple linear regression. Ascospores released and the percent ascospore release (the number of ascospores released expressed as a percentage of total ascospores released in one season that were collected in a single spore sampler) were related to various weather variables collected throughout the duration of the project to determine the impact of environmental factors on ascospore release. The weather variables included leaf wetness, cumulative leaf wetness duration, minimum temperature, average temperature, maximum temperature, dew point, duration of temperature $>4^{\circ} \mathrm{C}$, precipitation, precipitation event duration, bark wetness, cumulative bark wetness duration, and relative humidity. Data transformations of ascospore release data, both ascospore quantity and percent ascospore release, were assessed, including the log, logit, first derivative, and arcsin transformations. Model and data transformations were chosen based on the $R^{2}$ in a linear regression of observed ascospore release. The correspondence of predicted ascospore release events to observed ascospore release events was assessed using a two-by-two contingency table and Fisher's exact test, as described above.

\section{Results}

Period of ascospore release. During the 3 years of the experiment, 1,945 samples were assessed from the sampling array and 357 samples were assessed from the naturally infested vineyard. Ascospore release from both field and ascospore sampling array occurred from the onset of precipitation events in the autumn through the start of the following growing season in all three overwintering periods, and the last collections occurred on 27 May 2013, 1 July 2014, and 4 May 2015 (Fig. 2). Although, in 2013, chasmothecia were stored at $4{ }^{\circ} \mathrm{C}$ until they were placed in the sampling array, the release events were similar to the other 2 years, with no significant differences between average percent ascospore release after the first release event (Fig. 2). Ascospore release was observed from both artificial and natural bark. There was no effect on ascospore release from chasmothecia collected from different locations. Additionally, there was no difference observed in ascospore release events from natural and artificial barks. No detections occurred in noninoculated artificial or noninoculated natural grape bark treatments from the first rain until the cessation of sampling, indicating no detectable cross-contamination within the ascospore sampling array.

Comparison of ascospore release models. Using the fieldcollected ascospore release data set to assess model predictions, the UC Davis Risk Index ascospore release predictions were significantly correlated to observed ascospore release in all years $(P=$ 0.03 ; Table 1). This model's predicted ascospore release had a misclassification rate of $48 \%, 52 \%$ overall accuracy, $45 \%$ sensitivity, and $78 \%$ specificity. Predicted ascospore release by the Gadoury and Pearson model was not different from random chance in all years $(P=0.34$; Table 1$)$. This model had a $39 \%$ misclassification rate, $61 \%$ accuracy, $63 \%$ sensitivity, and $52 \%$ specificity. Ascospore release predictions from the Moyer ascospore release model showed no relationship to observed ascospore release magnitude in 2012-13 $\left(R^{2}=0, \rho=0.38\right), 2013-14\left(R^{2}=0, \rho=-0.31\right)$, and 2014-15 $\left(R^{2}=0, \rho=-0.18\right)$ overwintering periods (Fig. 3, top row). In predicting binary release events, the Moyer model had a misclassification rate of $45 \%, 55 \%$ accuracy, $64 \%$ sensitivity, and $22 \%$ specificity $(P=0.25$; Table 1$)$. Predicted ascospore release magnitude from the Caffi model also showed no relationship to 
observed ascospore release magnitude in the 2012-13 $\left(R^{2}=0, \rho=\right.$ $0.10), 2013-14\left(R^{2}=0, \rho=-0.17\right)$, and 2014-15 $\left(R^{2}=0, \rho=\right.$ 0.13 ) overwintering periods (Fig. 3, second row). Predicting binary release events, the Caffi model had a misclassification rate of $43 \%$, $57 \%$ accuracy, $73 \%$ sensitivity, and $4 \%$ specificity $(P=0.01$; Table 1).
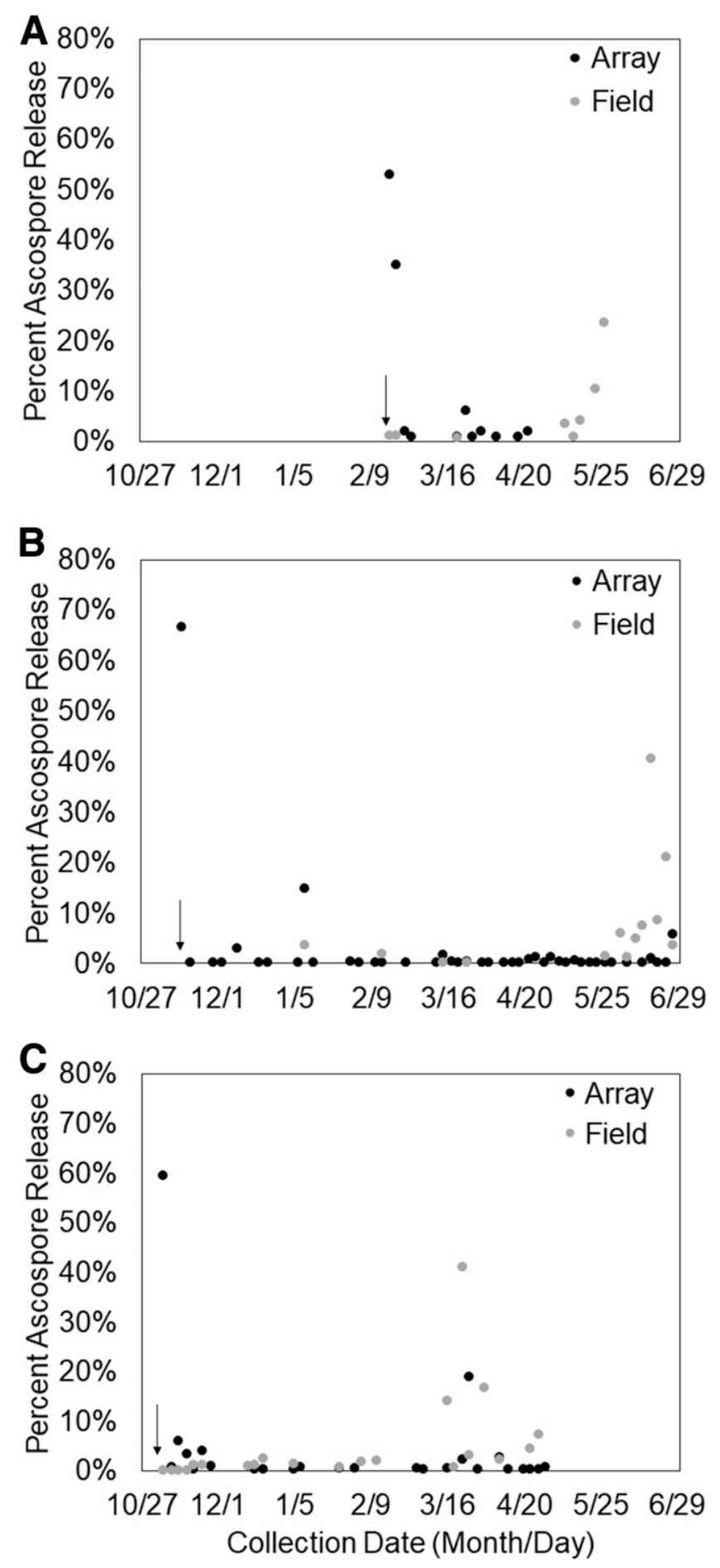

Fig. 2. Observed release events of ascospores of Erysiphe necator from an inoculated sampling array (black dots) and from a naturally infested research vineyard (gray dots) collected during the A, 2012-13; B, 2013-14; and C, 2014-15 grape dormancy seasons under natural conditions. Black arrows indicate the start of ascospore sampling from the field and within the sampling array for each period of chasmothecia overwintering. Ascospore samples were collected every 3 to 4 days, whereby DNA from samples was extracted and enumerated using a quantitative polymerase chain reaction assay. Samples without detectable ascospores are not shown for clarity.
Environmental factors affecting ascospore release. Environmental conditions were variable between each season of testing (Fig. 4) but could not be correlated to observed magnitude of ascospore release events $\left(R^{2}<0.10\right)$. Therefore, a daily binary ascospore release model (Oregon model, equation 5) was developed based on weather variables (described below) correlated with ascospore detections observed in the sampling array datasets. Ascospore release (A), predicted as 1 (occurrence of release) or 0 (no release), is a function of whether, within a 24-h period, there was more than $6 \mathrm{~h}$ of cumulative leaf wetness during temperatures above $4{ }^{\circ} \mathrm{C}\left(\mathrm{W}_{\mathrm{T} 4}\right)$, precipitation greater than $2.5 \mathrm{~mm}(\mathrm{P})$, and relative humidity $>80 \%(\mathrm{R})$, where the presence of each environmental condition is also represented as 1 and the absence as 0 .

$$
\mathrm{A}=\mathrm{W}_{\mathrm{T} 4} \times \mathrm{P} \times \mathrm{R}
$$

The Oregon model was validated using field-collected ascospore datasets and predicted ascospore release with a misclassification rate of $34 \%$ and $66 \%$ accuracy $(P=0.02)$ between observed and predicted ascospore release events (Table 1 ). The predicted values also showed $56 \%$ specificity and $68 \%$ sensitivity compared with field-observed values.

\section{Discussion}

Ascospore release models from different grape production regions inaccurately predicted ascospore release events in the Willamette Valley of Oregon (Table 1) and were unable to predict the magnitude of ascospore release observed in the field (Fig. 3). Each model frequently predicted no ascospore release when release was detected, indicating that the models are not adequate in discerning when chasmothecia dehiscence would occur. Because the severity of a polycyclic disease epidemic is largely dependent on effectively managing the epidemic rate (Madden et al. 2007), ascospore release needs to be accurately predicted to efficiently implement management practices during the lag phase. Because the models assessed and developed in this study had accuracies below 70\%, with high misclassification rates (34 to $78 \%$ ), their use would likely result in economic losses due to unnecessary fungicide applications (caused by false positives) or poorly timed management decisions (false negatives delaying application) that result in crop damage. However, the impact of poorly timed fungicides caused by these inaccuracies is not known. It is likely that false negatives will have less impact on grape

Table 1. Contingency table representing model predicted ascospore release compared with observed field ascospore release for all overwintering periods between 2013 and 2015

\begin{tabular}{|c|c|c|c|c|}
\hline \multirow[b]{2}{*}{ Model $^{\mathbf{b}}$} & \multirow[b]{2}{*}{ Predicted $^{\mathrm{c}}$} & \multicolumn{2}{|c|}{ Observed $^{\mathbf{a}}$} & \multirow[b]{2}{*}{ Probability $^{\mathrm{d}}$} \\
\hline & & Positive & Negative & \\
\hline \multirow[t]{2}{*}{ Oregon predicted } & Positive & 15 & 29 & 0.02 \\
\hline & Negative & 12 & 63 & ... \\
\hline \multirow[t]{2}{*}{ UC Davis Index predicted } & Positive & 21 & 51 & 0.03 \\
\hline & Negative & 6 & 41 & $\ldots$ \\
\hline \multirow[t]{2}{*}{ Gadoury Pearson predicted } & Positive & 14 & 34 & 0.34 \\
\hline & Negative & 13 & 58 & $\ldots$ \\
\hline \multirow[t]{2}{*}{ Moyer Binary predicted } & Positive & 6 & 33 & 0.25 \\
\hline & Negative & 21 & 59 & $\ldots$ \\
\hline \multirow[t]{2}{*}{ Caffi Binary predicted } & Positive & 1 & 25 & 0.01 \\
\hline & Negative & 26 & 67 & $\ldots$ \\
\hline
\end{tabular}

a "Positive" and "Negative" indicate the number of samples for which Erysiphe necator DNA was detected and not detected, respectively, using the quantitative polymerase chain reaction assay based on TaqMan probe with minor groove binder.

${ }^{b}$ Model parameters for the Oregon model, University of California (UC) Davis Risk Index, Gadoury and Pearson model, Moyer model, and Caffi model are presented in the text.

$c$ "Positive" and "Negative" indicate the number of samples for which E. necator ascospore release was predicted to occur or not occur, respectively, based on the binary ascospore release model as described in the text.

d Fisher's exact test was used to assess the null hypothesis that the observed ascospore release was correlated to the model predicted ascospore release. 
powdery mildew in practice than false-positive predictions. The generation time of $E$. necator during the weather typical of early spring is approximately 14 days (Delp 1954). In addition, Moyer et al. (2016) showed that, when the temperature was below $8^{\circ} \mathrm{C}$ for just a few hours, there was significant reduction in E. necator infection frequency and colony expansion. This could indicate that, during periods when minimum temperatures are below $8^{\circ} \mathrm{C}$, grape powdery mildew management will be less susceptible to false-negative

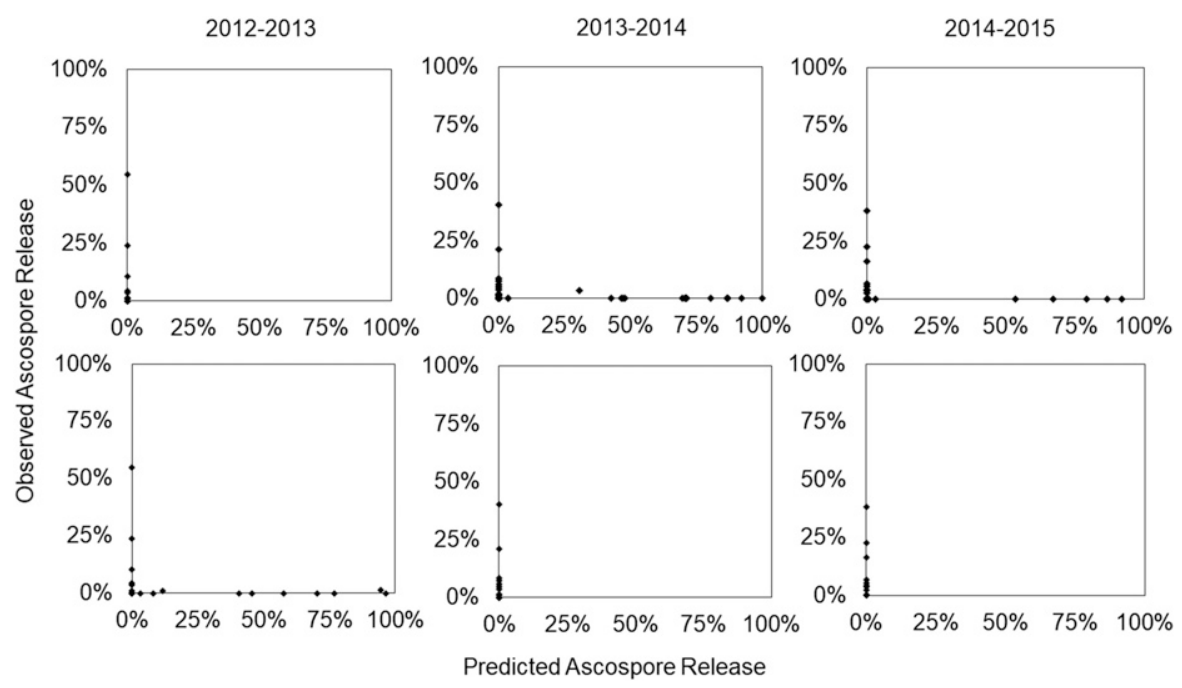

Fig. 3. Observed Erysiphe necator ascospore release magnitude (Y-axis) compared with predicted ascospore release magnitude (X-axis) of three previously developed models (Caffi et al. 2011; Moyer et al. 2014). Predicted ascospore release magnitude was generated using environmental data collected from the 2012-2103 (left column), 2013-14 (middle column), and 2014-15 (right column) grape dormancy seasons using the Moyer et al. (2014) ascospore release model predicting percent ascospore release (top row) and Caffi et al. (2011) mechanistic model predicting ascospore quantity (bottom row). In comparing observed versus predicted ascospore release, the Moyer model (top row) showed low correlation to observed release events in 2012-13 $\left(R^{2}=0, \rho=0.38\right), 2013-14\left(R^{2}=0, \rho=-0.31\right)$, and 2014-15 $\left(R^{2}=0, \rho=-0.18\right)$. The Caffi model (bottom row) showed low correlation to observed release events in the 2012-13 $\left(R^{2}=0, \rho=0.10\right), 2013-14\left(R^{2}=0, \rho=-0.17\right)$, and 2014-15 $\left(R^{2}=0, \rho=0.13\right)$ overwintering periods.
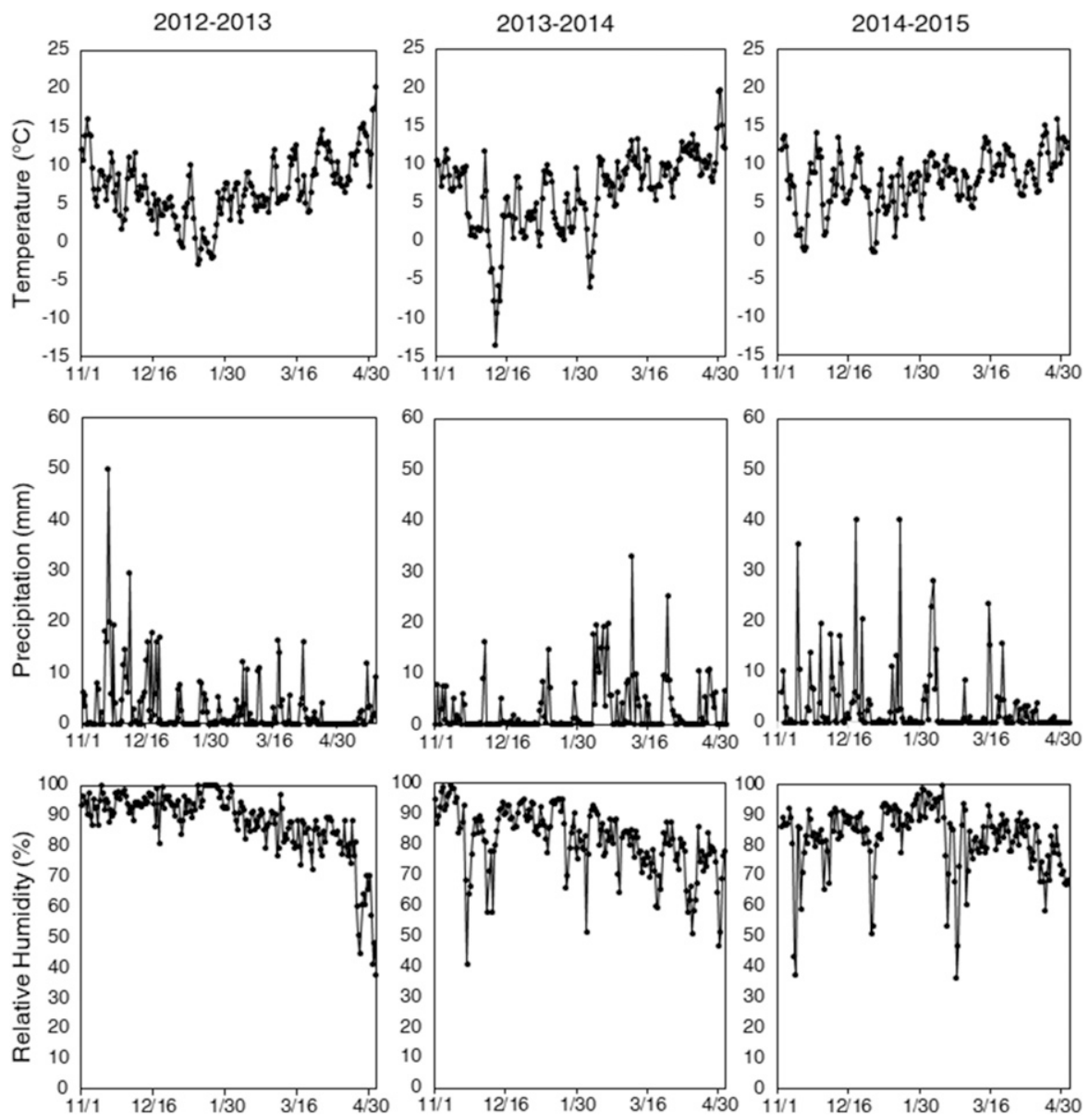

Fig. 4. Observed temperature $\left({ }^{\circ} \mathrm{C}\right.$, top row), precipitation (millimeters, middle row), and relative humidity (percent, bottom row) during the 2012-13 (left column), 2013-14 (middle column), and 2014-15 (right column) ascospore release capture seasons. Seasons for ascospore release capture were significantly different $(P<0.001)$, and weather variables for each season were compared with ascospore release. 
prediction than false-positive predictions. However, in periods when temperature is conducive for pathogen development, false negatives could severely hinder disease management because the polycyclic epidemic would have faster rate of development (Madden et al. 2007).

All models evaluated that predicted the magnitude of ascospore release (Moyer and Caffi) showed no correlation $\left(R^{2}<0.01\right)$ to ascospore release magnitude observed in field conditions (Fig. 3), and regression analyses conducted in this study showed low correlations $\left(R^{2}<0.1\right)$ to any of the examined weather parameters. In addition, all the binary ascospore release models tested, including the Oregon model developed in this study, had significant rates of false negatives and positives (Table 1). These inaccuracies could be due to the asynchronous development of chasmothecia cohorts, which are affected by the duration of time that E. necator isolates are within close proximity to a compatible mating type (Gadoury and Pearson 1988), variability in the quantity of total chasmothecia produced, and number of ascospores produced with each chasmothecium. The maturation of chasmothecia and ascospores are also not considered, which may explain periods of time when conditions are conducive for ascospore release with no observable release events. The specific conditions for chasmothecia and ascospore maturation are not well understood, with mature chasmothecia only visually described as having turned dark brown to black with a concave depression in the hull (Gadoury and Pearson 1988).

A degree-day model utilizing temperatures required for chasmothecia maturation may be useful in describing ascospore release. Moyer et al. (2014) used $500 \mathrm{DD}_{0}$ to describe chasmothecia maturation using in vitro data from a previous study (Gadoury and Pearson 1988). The nonlinear equations for the production of chasmothecia developed by Legler et al. (2012) are based on the temperature and fit to a Gompertz model, which overestimates chasmothecia production. This chasmothecia production model also requires the specific date of chasmothecia primordia initiation to accurately predict chasmothecia production (Legler et al. 2012), which is not practical for vineyard managers. Generating a broadly accurate and practical chasmothecia production model would be difficult due to the inability to predict when compatible mating types are within close proximity and when chasmothecia production is initiated in a naturally infested vineyard (Cortesi et al. 1997; Gadoury and Pearson 1990b; Gee et al. 2000; Moyer et al. 2014; Pearson and Gadoury 1987). In temperate regions such as the Willamette Valley of Oregon, there is usually a long period between the last fungicide application (approximately véraison, mid-August) and leaf drop (mid-November) that allows for extensive disease development along with continued production of susceptible host tissue on lateral shoots. These conditions could result in the development of chasmothecia cohorts that may differentially mature during overwintering and, subsequently, require several unknown factors before they mature enough to dehisce during periods of moisture and warm temperatures.

Over the course of the 3 years of this study, environmental conditions were conducive for chasmothecia dehiscence and subsequent ascospore release during autumn and winter months, with approximately $87 \%$ of the total ascospores captured during the period before bud break. Because E. necator requires green, susceptible grape tissues to infect and survive (Gadoury et al. 2012), this asynchrony between chasmothecia dehiscence and host tissue availability results in a large portion of the potential overwintering inoculum failing to cause new infections. The release of ascospores prior to host tissue availability may be related to the local adaption of the host and the pathogen to differing climates. E. necator is thought to originate from the warm, temperate climate of southeastern North America (Brewer and Milgroom 2010), where the regional environment is characterized by hot, wet summers and cool, dry winters (Kottek et al. 2006). Thus, E. necator evolved to overwinter in a cool, dry climate, and it is likely that these evolutionary adaptations to this climate affect the development and dehiscence of chasmothecia in regions with dissimilar climates. Moyer et al. (2014) observed that more than 50\% of the primary inoculum available was lost due to chasmothecia dehiscence prior to bud break in five regions across the United States, which is in agreement with the data presented here. Additionally, chasmothecia that developed in regions with warmer overwintering conditions were mature enough for release during the winter (Moyer et al. 2014). Other studies have also reported dehiscence occurring in autumn (Gee et al. 2000; Grove 2004; Thomas et al. 1994) or before bud break (Gee et al. 2000; Grove 2004; Moyer et al. 2014; Rossi et al. 2010). The observations reported here also indicate that there is likely some stochastic response to environmental stimuli from E. necator chasmothecia because only occasionally did all three replications for the field or all four replications for the array have positive detections at the same time. This type of response should be expected because it would likely be detrimental to survival of an organism for all individuals to transition from overwintering to ascospore release at the same time. These observations indicate that an improved understanding of chasmothecia maturation and factors involved in chasmothecia dehiscence is needed to better estimate ascospore release after bud break.

Quantification and prediction of ascocarp maturation and ascospore release of an obligate biotroph is difficult and not without potential tradeoffs in experimental approaches. The limited predictive values of ascospore release models observed in this study may be a function of the ascospore collection methods used to develop the empirical relationships. Lab-induced ascospore release from chasmothecia that have been overwintered in vineyards (Gadoury and Pearson 1990a; Moyer et al. 2014) requires simplification of the environmental conditions that induce ascospore release. Providing free moisture and temperatures between 22 and $25^{\circ} \mathrm{C}$ excludes potentially important environmental conditions that may influence ascospore release and may cause premature release of ascospores that would not have occurred naturally under less optimal environmental conditions. Similarly, the use of the physical observation of E. necator ascosporic infections (Caffi et al. 2011; Thomas et al. 1994) may inaccurately predict ascospore release because it likely underestimates ascospore release by not accounting for ascospore loss due to unsuitable conditions for infection or ascospores that did not land on susceptible host tissue. Examining the leaf tissue for ascosporic infections may also mischaracterize infections initiated by conidia, leading to overestimation of ascospore release. It is also possible that the assessment methods used in this study could overestimate ascospore release because the qPCR assay cannot distinguish ascospores from conidia, nondehiscent chasmothecia washed from trunks, or nonviable spores, because all would result in a positive qPCR detection. It is not likely that chasmothecia were present in samples because intact chasmothecia are not lysed by the extraction procedure used (T. M. Neill, personal observation). It is also possible that the spore samplers within the field did not capture all ascospores that were released. Although the samplers were placed directly adjacent to the bark of the grape trunk in the vineyard sampling, the distance from the trunk and the position of the trap on the side of the trunk, as opposed to underneath the inoculum as in the array (Fig. 1), could have reduced the ability of the samplers to collect ascospores that were only ejected a few millimeters away from the chasmothecia (Aylor 1993; Gregory 1973). This could be particularly true during rain events or when there was little or no air turbulence (Miller et al. 2015), although the small spore size would increase the probability of drifting on the convective fluxes (e.g., air currents) (Aylor 2017). Although sampling inefficiency may have missed a few release events, it is unlikely to explain the magnitude of the misclassification error of all models tested, indicating that the models are missing some component of the pathogen's biology.

There were a number of differences between the ascospore release data from the array and field-collected ascospores. The peak ascospore release, as percentage of the total release observed, occurred during the first one or two rain events each season in the array data set whereas the peak occurred near bud break in the field dataset. This difference is likely because chasmothecia were collected prior to the first fall precipitation event and stored at $4^{\circ} \mathrm{C}$ until after leaf drop. The field ascospore release sampling could not occur until after the first frost or leaf drop due to actively sporulating E. necator colonies until the first frost in all years and the inability to distinguish conidia from 
ascospores. It is also likely that the field data set does not contain all of the potential ascospores released because sampling did not occur during several precipitation events that occurred prior to leaf drop. It is important to note that, although the percentage of ascospores release from the two environments differed, the magnitude of the ascospore release events in terms of actual spores detected did not significantly differ among any sample after the initial releases observed in the arrays (data not shown). These results indicate that similar chasmothecia maturation and release was occurring in both the field and array sampling.

In contrast to previous reports (Gadoury and Pearson 1990a; Gee et al. 2000; Jailloux et al. 1998; Moyer et al. 2014), repeated cyclical wetting was not required for ascospore release to occur in this study and release was observed at the first sufficient precipitation event in all years. The chasmothecia for this experiment were not exposed to moisture prior to placement in the ascospore sampling array; thus, the immediate release of ascospores upon wetting of chasmothecia suggests that factors other than cyclical wetting prior to favorable temperatures may affect chasmothecia rupturing. Temperature appears to be the only environmentally limiting condition required for the maturation of chasmothecia and the viability of ascospores (Diehl and Heintz 1987; Gadoury and Pearson 1988). During the maturation process, the development and utilization of lipid and sugar components within the chasmothecium occur (Gadoury and Pearson 1988), and this consumption of resources may be associated with the viability of released ascospores (Gadoury and Pearson 1990b). Hydrophobic lipid contents that decrease as chasmothecia mature (Gadoury and Pearson 1988) may also affect the uptake of water into chasmothecia and subsequent rupturing of the ascocarp wall. In the Willamette Valley of Oregon, chasmothecia develop and mature asynchronously and, by leaf fall (BBCH 93 to 97), different cohorts of chasmothecia are produced and deposited within the grape bark (L. D. Thiessen, personal observation). Asynchronous lipid production and utilization may also prevent depletion of initial inoculum prior to the start of the following growing season, despite conducive conditions for release throughout the duration of grape dormancy. This may also reduce the ability to predict ascospore release magnitude and depletion; thus, a binary model may be more practical for vineyard management decisions.

The Gadoury and Pearson, UC Davis, and Oregon models appear to be equally representative of ascospore release events (though relatively inaccurate) occurring in the Willamette Valley. In this study, ascospore release events were generally observed when leaf wetness occurred simultaneously with temperatures $>4^{\circ} \mathrm{C}$, daily average relative humidity $>80 \%$, and precipitation events $\geq 2.5 \mathrm{~mm}$. These conditions are common to the Mediterranean climate $(\mathrm{Csb})$ of much of the Pacific Northwest of the United States, the southernmost part of Chile, parts of west-central Argentina, parts of southern Europe, and parts of New Zealand (Kottek et al. 2006). These regions are characterized by dry summers and mild, rainy winters (Kottek et al. 2006). The winter conditions in these regions are often wet, with average temperatures $>4^{\circ} \mathrm{C}$ and, thus, suitable for ascospore release. The significance of high relative humidity is also consistent with ascospore release of other Ascomycete fungi (Fernando et al. 2000; Mondal et al. 2003; Osborne and Stein 2007; Pinkerton et al. 1998), which suggests that it is important to consider in E. necator ascospore release. The temperature and moisture thresholds used in this study are similar to conditions reported in other regions (Caffi et al. 2011; Falacy et al. 2007; Gee et al. 2000; Jailloux et al. 1999; Rossi et al. 2010). Counterintuitively, the leaf wetness duration correlated with ascospore release events whereas bark wetness duration measures were uncorrelated $(P>0.1)$, which may be associated with the bark wetness measurements used or the fact that barkwetness events often extended across sampling times. Hall (2000) also found that the addition of bark-wetness measurements from grape trunks did not improve prediction of ascospore release for the UC Davis and Gadoury and Pearson models. These results could indicate that leaf wetness is a good surrogate for identifying when there is sufficient free moisture available for chasmothecia imbibition and to trigger dehiscence (Gadoury and Pearson 1990a).
The data presented indicate that factors other than free moisture availability and temperature influence ascocarp dehiscence and ascospore release. Ascospore release occurred throughout the fall and into the following growing season, and ascosporic inoculum was not exhausted until well into spring and early summer. The last collection occurred on 27 May to 1 July, despite the occurrence of numerous periods of conducive conditions for chasmothecia dehiscence. No extant predictive systems capture this phenomenon well, and predicting E. necator ascospore release and subsequent disease development based solely on environmental conditions may not be possible in wet, temperate regions. Further investigation of E. necator overwintering and ascospore release biology may help to clarify ascospore release conditions that are not explained by environmental variables.

\section{Acknowledgments}

We thank C. Provence, C. Gorman, M. Evers, and B. Williams for technical support; Z. Kamvar and J. Tabima for data analysis support; and the reviewers for their helpful suggestions to improve the manuscript.

\section{Literature Cited}

Aylor, D. E. 1993. Relative collection efficiency of Rotorod and Burkard spore samplers for airborne Venturia inaequalis ascospores. Phytopathology 83: 1116-1119.

Aylor, D. E. 2017. Aerial Dispersal of Pollen and Spores. American Phytopathological Society, St. Paul, MN.

Braun, U., and Takamatsu, S. 2013. Phylogeny of Erysiphe, Microsphaera, Uncinula (Erysipheae) and Cystotheca, Podosphaera, Sphaerotheca (Cystotheceae) inferred from rDNA ITS sequences-Some taxonomic consequences. Schlechtendalia (Halle) 4:1-33.

Brewer, M. T., and Milgroom, M. G. 2010. Phylogeography and population structure of the grape powdery mildew fungus, Erysiphe necator, from diverse Vitis species. BMC Evol. Biol. 10:268.

Caffi, T., Rossi, V., Legler, S. E., and Bugiani, R. 2011. A mechanistic model simulating ascosporic infections by Erysiphe necator, the powdery mildew fungus of grapevine. Plant Pathol. 60:522-531.

Chellemi, D. O., and Marois, J. J. 1991. Development of a demographic growth model for Uncinula necator by using a microcomputer spreadsheet program. Phytopathology 81:250-254.

Cortesi, P., Bisiach, M., Ricciolini, M., and Gadoury, D. M. 1997. Cleistothecia of Uncinula necator-an additional source of inoculum in Italian vineyards. Plant Dis. 81:922-926.

Delp, J. 1954. Effect of temperature and humidity on the grape powdery mildew fungus. Phytopathology 44:615-626.

Diehl, H., and Heintz, C. 1987. Studies on the generative reproduction of grapevine powdery mildew (Uncinula necator (Schw.) Burr.). Vitis 26:114-122.

Falacy, J. S., Grove, G. G., Mahaffee, W. F., Galloway, H., Glawe, D. A., Larsen, R. C., and Vandemark, G. J. 2007. Detection of Erysiphe necator in air samples using the polymerase chain reaction and species-specific primers. Phytopathology 97:1290-1297.

Fawcett, T. 2006. An introduction to ROC analysis. Pattern Recognit. Lett. 27: 861-874.

Fernando, W. G., Miller, J., Seaman, W., Seifert, K., and Paulitz, T. 2000. Daily and seasonal dynamics of airborne spores of Fusarium graminearum and other Fusarium species sampled over wheat plots. Can. J. Bot. 78:497-505.

Gadoury, D. M., Cadle-Davidson, L., Wilcox, W. F., Dry, I. B., Seem, R. C., and Milgroom, M. G. 2012. Grapevine powdery mildew (Erysiphe necator): A fascinating system for the study of the biology, ecology and epidemiology of an obligate biotroph. Mol. Plant Pathol. 13:1-16.

Gadoury, D. M., and Pearson, R. C. 1988. Initiation, development, dispersal and survival of cleistothecia of Uncinula necator in New York vineyards. Phytopathology 78:1413-1421.

Gadoury, D. M., and Pearson, R. C. 1990a. Ascocarp dehiscence and ascospore discharge in Uncinula necator. Phytopathology 80:393-401.

Gadoury, D. M., and Pearson, R. C. 1990b. Germination of ascospores and infection of Vitis by Uncinula necator. Phytopathology 80:1198-1203.

Gee, L. M., Stummer, B. E., Gadoury, D. M., Biggins, L. T., and Scott, E. S. 2000. Maturation of cleistothecia of Uncinula necator (powdery mildew) and release of ascospores in southern Australia. Aust. J. Grape Wine Res. 6:13-20.

Gregory, P. H. 1973. The Microbiology of the Atmosphere, 2nd ed. Leonard Hill, London.

Grove, G. G. 2004. Perennation of Uncinula necator in Vineyards of Eastern Washington. Plant Dis. 88:242-247.

Gubler, W. D., Rademacher, M. R., Vasquez, S. J., and Thomas, C. S. 1999. Control of powdery mildew using the UC Davis powdery mildew risk index. Online publication. APSnet Features. http://www.apsnet.org/publications/ apsnetfeatures/Pages/UCDavisRisk.aspx

Hall, T. 2000. Epidemiology of Grape Powdery Mildew, Uncinula necator, in the Willamette Valley. Oregon State University, Corvallis. 
Jailloux, F., Thind, T., and Clerjeau, M. 1998. Release, germination, and pathogenicity of ascospores of Uncinula necator under controlled conditions. Can. J. Bot. 76:777-781.

Jailloux, F., Willocquet, L., Chapuis, L., and Froidefond, G. 1999. Effect of weather factors on the release of ascospores of Uncinula necator, the cause of grape powdery mildew, in the Bordeaux region. Can. J. Bot. 77:1044-1051.

Kottek, M., Grieser, J., Beck, C., Rudolf, B., and Rubel, F. 2006. World map of the Köppen-Geiger climate classification updated. Meteorol. Z. 15:259-263.

Legler, S. E., Caffi, T., and Rossi, V. 2012. A nonlinear model for temperaturedependent development of Erysiphe necator chasmothecia on grapevine leaves. Plant Pathol. 61:96-105.

Lorenz, D. H., Eichhorn, K. W., Bleiholder, H., Klose, R., Meier, U., and Weber, E. 1995. Growth stages of the grapevine: Phenological growth stages of the grapevine (Vitis vinifera L. ssp. vinifera) — Codes and descriptions according to the extended BBCH scale. Aust. J. Grape Wine Res. 1:100-103.

Madden, L. V., Hughes, G., and Van den Bosch, F. 2007. The Study of Plant Disease Epidemics. American Phytopathological Society, St. Paul, MN.

Miller, N. E., Stoll, R., Mahaffee, W. F., Neill, T. M., and Pardyjak, E. R. 2015. An experimental study of momentum and heavy particle transport in a trellised agricultural canopy. Agric. For. Meteorol. 211-212:100-114.

Mondal, S., Gottwald, T., and Timmer, L. 2003. Environmental factors affecting the release and dispersal of ascospores of Mycosphaerella citri. Phytopathology 93:1031-1036

Moyer, M. M., Gadoury, D. M., Wilcox, W. F., and Seem, R. C. 2014. Release of Erysiphe necator ascospores and impact of early season disease pressure on Vitis vinifera fruit infection. Am. J. Enol. Vitic. 65:315-324.
Moyer, M. M., Londo, J., Gadoury, D. M., and Cadle-Davidson, L. 2016. Cold stress-induced disease resistance (SIDR): Indirect effects of low temperatures on host-pathogen interactions and disease progress in the grapevine powdery mildew pathosystem. Eur. J. Plant Pathol. 144:695-705.

Osborne, L. E., and Stein, J. M. 2007. Epidemiology of Fusarium head bligh on small-grain cereals. Int. J. Food Microbiol. 119:103-108.

Pearson, R. C., and Gadoury, D. M. 1987. Cleistothecia, the source of primary inoculum for grape powdery mildew in New York. Phytopathology 77 1509-1514.

Pinkerton, J., Johnson, K., Stone, J., and Ivors, K. 1998. Factors affecting the release of ascospores of Anisogramma anomala. Phytopathology 88 122-128.

Pscheidt, J. W., Wittig, H. P. P., Wallace, L. D., Hall, T., and Mahaffee, W. 2000. Evaluation of three grape powdery mildew forecasting programs in Corvallis, Oregon, USA. Pages 143-146 in: SARDI Research Report Series. S. A. Margarey Thiele, K. L. Tschirpig, R. W. Emmett, K. Clarke, and R. D. Margarey, eds. Adelaide, Australia.

Rossi, V., Caffi, T., Legler, S. E., and Cattolica, U. 2010. Dynamics of ascospore maturation and discharge in Erysiphe necator, the causal agent of grape powdery mildew. Phytopathology 100:1321-1329.

Thiessen, L. D., Keune, J. A., Neill, T. M., Turechek, W. W., Grove, G. G., and Mahaffee, W. F. 2016. Development of a grower-conducted inoculum detection assay for management of grape powdery mildew. Plant Pathol. 65:238-249.

Thomas, C. S., Gubler, W. D., and Leavitt, G. 1994. Field testing of a powdery mildew disease forecast model on grapes in California. (Abstr.) Phytopathology $84: 1070$. 